\title{
Los esquemas de aprendizaje: Kant y Piaget. Introducción filosófica-psicológica
}

\author{
Álvaro Escobar Soriano \\ Universidad Nacional Autónoma de Nicaragua, Managua \\ UNAN-Managua \\ alvess007@gmail.com
}

DOI: $h t t p: / / d x$. doi.org/10.5377/torreon.v6i16.6557

Palabras claves: sistema conceptual, esquema, aprendizaje, fases, sujeto-objeto

\section{RESUMEN}

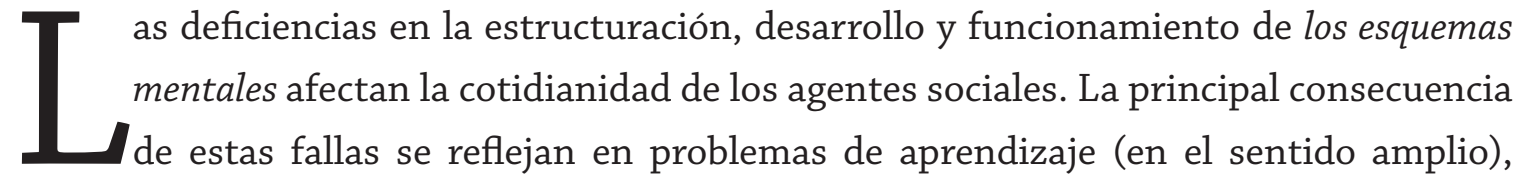
desde problemas meramente técnicos hasta errores en el pensamiento lógico-matemático, en el pensamiento crítico-social y en las habilidades naturales y artificiales del lenguaje: expresión oral, expresión escrita, comprensión lectora y gramática).

Estudiar los esquemas de aprendizaje humano trae a la luz que el hombre y la realidad son dinámicos y complejos, por tanto, se puede plantear que, la acción y el aprendizaje humano se construyen a partir de un tejido polisimbiótico-social individual o colectivo que se manifiesta en el discurso y permite explicitar los esquemas de aprendizaje estructurados a partir de cuatro subesquemas de acción: conceptual-factual, lingüístico, sociocultural y técnico-procedimental, que funcionan al unísono, aunque en diferente orden cuando entran en contacto con las situaciones de aprendizaje práctica o teóricas.

El origen actual de la teoría de esquemas nace con Kant, quién, en su sistema conceptual, desarrolla una visión teórica sobre estos. Así, parte de la necesidad de comprender de qué manera es posible que un objeto sea conceptualizado por la mente y crea el concepto de esquema trascendental como categoría que hace posible la representación no empírica, pero sí intelectual 
y sensible de los objetos en los conceptos. Este término, doblemente homogéneo, lleva implícito la categoría tiempo, las relaciones entre las representaciones y las representaciones, a decir, es un microsistema que permite la categorización de los fenómenos como conceptos objetos de conocimiento. El método que sigue el entendimiento respecto a este esquema, lo llama esquematismo del entendimiento puro.

Con base en las ideas de Kant y los aportes de un especialista francés, Piaget, coloca el concepto esquema como término central y evolutivo, que permite describir la acción del sujeto durante una situación específica de aprendizaje, por tanto, para explicar el funcionamiento cognitivo del sujeto. Por ello, se puede observar, a lo largo de la obra piagetiana, dos tesis fundamentales para explicar la interacción sujeto-objeto, quien utiliza el concepto esquema relacionado directamente con la acción, lo cual le permitió explicitarlo.

\section{Introducción}

Desde los albores de la humanidad -en las antiguas civilizaciones hititas, mayas, egipcia, azteca, china, inca, europeas (griega y romana), hasta la actualidad- el conocimiento se ha constituido a partir de un poderoso instrumento: la interacción social. Esta es la principal mediadora, en sentido amplio y estricto, entre la enseñanza y el aprendizaje en situaciones informales y formales de actuación en las cuales están presentes un agente que enseña y otro que aprende.

Así, desde las situaciones cotidianas hasta las académica-científicas, en la actualidad, necesitan el desarrollo efectivo de los esquemas de aprendizaje de las personas mediante un proceso recursivo que requiere de acciones mentales como la estructuración, la reestructuración y la fijación. Sin embargo, no todos los seres humanos alcanzan esquemas expertos por diferentes razones evolutivas: histórico-culturales, sociales, la incertidumbre de los hábitat humanos o una mezcla de ellas.

Las deficiencias en la estructuración, desarrollo y funcionamiento de los esquemas mentales afectan la cotidianidad de los agentes sociales. La principal consecuencia de estas fallas se reflejan en problemas de aprendizaje (en el sentido amplio), de la técnica, del pensamiento lógico-matemático, del pensamiento crítico-social, de las habilidades naturales y artificiales del lenguaje (habla y escucha, lectura y escritura), y su uso inadecuado en los diferentes campos profesionales: actuaciones deficientes en la interacción social, serias contradicciones en la resolución de problemas y en la toma de decisiones, fallas en el manejo de la tecnología, resultados poco satisfactorios en el campo de la investigación y clara evidencia de mal empleo de las competencias lingüísticas (expresión oral, expresión escrita, comprensión lectora y gramática). 
Estudiar los esquemas de aprendizaje humano trae a la luz que el hombre y la realidad son dinámicos y complejos. Por tanto, se requiere considerar dos aspectos fundamentales del andamiaje sistémico de la mente que permiten analizarlos: 1) la complejidad psicobiológica y social de la mente humana es una especie de interfaz mediadora entre el ser (consciente o subconsciente) y las policontexturas de la realidad que se le revelan; 2) teniendo en cuenta los fundamentos filosóficos de la lógica policontextural ${ }^{1}$ se puede plantear que la acción y el aprendizaje humano se construyen a partir de un tejido polisimbiótico-social individual o colectivo que se manifiesta en el discurso y permite explicitar los esquemas de aprendizaje estructurados a partir de cuatro subesquemas de acción: conceptual-factual, lingüístico, sociocultural y técnico-procedimental, que funcionan al unísono aunque en diferente orden cuando entran en contacto con las situaciones de aprendizaje práctica o teóricas.

El segundo aspecto, enumerado en el párrafo anterior, toma como referencia no solo la definición de policontextura, sino sus principales aportes sobre los sistemas autorreferenciales ${ }^{2}$. Según Salatino (2009), en estos sistemas se basa la teoría de la subjetividad que permite observar la posible interacción entre volición y cognición:

- Eliminación de la ambigüedad en la representación de la relación S/O.

- La identidad como posibilidad de contar con varias formas de expresión.

- El concepto de paralelismo justifica la manifestación simultánea de las formas de expresión de la identidad.

- Un nuevo proceso inductivo que se configura al considerar no solo al sistema, sino a la o las realidades fuera del sistema.

- Nuevas identidades: Sujeto (S), Objeto (O) y Sujeto Objetivo (SO) como valores lógicos.

- La heterarquía, contrapuesta a la jerarquía, representa la causalidad cíclica propia de los procesos jerárquicos distribuidos en distintas contexturas.

1. Günther (1979) en Salatino (2009, pp. 33-34) definió contextura "como el dominio en el que existen solo dos valores lógicos (dominio lógico binario). En este dominio en donde son respetados los postulados de la lógica clásica (principio de identidad, principio de no contradicción, principio del tercero excluido), estos valores asumen el rol de 'verdadero' y 'falso' (...) es un dominio en donde tiene vigencia un sujeto (S) que se erige como distinto a sus objetos (O), lo que constituye un cierto proceso de cognición [de ahí] la insuficiencia de solo dos valores (como los disponibles en un dominio mono-contextural) para tratar con otros aspectos verdaderos como los fenómenos habituales ligados a la percepción o el comportamiento o con los relacionados con el lenguaje cotidiano que muestran una aparente y compleja gradación".

2. Los sistemas autorreferenciales en el nivel operativo tienen la capacidad de diferenciar sus acciones de lo demás, es decir de su entorno. En este sentido, el sistema se realimenta con la información del medio en que habita o se desarrolla, considerando las diferentes disposiciones y concepciones teóricas respecto a esta diferencia. De aquí surgen las operaciones con las que el sistema funciona. Sin embargo, necesita un estado de adaptación continua a su entorno para superar la complejidad del procesamiento interno de información. Por tanto, un conocimiento con suficiente flexibilidad, posibilita la adaptación a situaciones de paso; por ello compensa la complejidad externa, aumentando la complejidad interna (Luhmann, 2002). También se relaciona con el concepto de autopoiesis que enfatiza el hecho de que los seres vivos son unidades autónomas (Maturana y Varela, 2003). 
Por tanto, investigar sobre el sistema ser humano parte de considerarlo en conjunto con la realidad en que habita y cómo aprende de ella. Así, estudiar los esquemas de acción humanos es orientarse sobre y bajo una línea de postulados de las ciencias cognitivas (psicología cognitiva, la neurociencia), relacionadas con la filosofía, la antropología, la lingüística, la sociología, la teoría de la cultura y el aprendizaje. Por consiguiente, es necesario partir de una concepción filosóficacientífica ecléctica y unificada, como base que permita comprender el origen de las ideas que los han conformado desde la antigüedad.

En lo subsiguiente, se plantea una serie de ideas que permiten comprender teóricamente qué son los esquemas mentales -desde la filosofía hasta la psicología genética- y su aplicación al estudio del aprendizaje. Estas conforman la base de la teoría sobre los subesquemas que conforman los esquemas de aprendizaje.

\section{Materiales y métodos}

Para fundamentar un trabajo de campo, especialmente el realizado en el aula de clase para explorar, observar y caracterizar los esquemas de aprendizaje gramatical de los estudiantes de II año (curso 2015) de la carrera Lengua y Literatura Hispánicas de la Facultad de Educación e Idiomas de la UNAN-Managua, primero fue necesario realizar una investigación documental. Con esta, se hizo un acercamiento a un núcleo de científicos y a las teorías principales en las que se basó la tesis doctoral "Esquemas de aprendizaje de la gramática”.

Por consiguiente, esta tuvo como eje metodológico la investigación de tipo documental. El principal método utilizado fue la búsqueda y rastreo de información, lo que se denomina método bibliográfico. De ahí que, De la Torre y Navarro (1982) expresen: "La adquisición u obtención del conocimiento, la fijación, organización y ampliación del mismo, así como su transmisión, requieren de normas especiales, de una metodología que precise y eduque en pensamiento y la expresión, que los estimule y fortalezca. Así pues, el método es un proceso lógico, surgido del raciocinio y de la inducción" (p. 3).

Considerando, que la obtención de la información ocurre de manera directa o indirecta, y este último procedimiento es común en la práctica investigativa actual (Sierra, 1986), el desarrollo de la temática: "El aprendizaje por esquemas: introducción filosófica-psicológica. Los esquemas de acción humanos: Kant y Piaget", centró su foco de selección en aquellos autores cuyo interés, inicialmente, fue poner en perspectiva una visión sobre cómo aprende el ser humano.

Otro método utilizado fue el análisis temático, el cual sirvió para extraer de los textos y artículos consultados, aquellos aspectos que tenían de manera explícita relación con el concepto de interés: esquema de acción. 
Predominó en la indagación como método de análisis, la conceptualización y la definición como estrategias que conforman el método interpretativo. Con este, se focalizó los planteamientos centrales de los dos principales teóricos que originaron el concepto esquema como categoría de análisis del conocimiento y aprendizaje humano. Kant, desde la filosofía racionalista y Piaget, desde la observación empírica de corte psicológico-genético.

Finalmente, el análisis y discusión teórica se presenta de manera evolutiva, es decir, como reconstrucción histórico-teórica desde el campo de la filosofía hacia el de la psicología genética.

\section{De Kant a Piaget: los esquemas de acción humanos}

Kant en su sistema conceptual desarrolla una visión teórica sobre los esquemas. En su Crítica de la Razón Pura, se encuentra un capítulo breve sobre el esquematismo de los conceptos puros del entendimiento. Parte de la necesidad de comprender de qué manera es posible que un objeto sea conceptualizado por la mente, si la única forma es que: "la representación del primero debe ser homogénea a la del segundo, es decir, el concepto debe encerrar lo que es representado en el objeto. Que es, en efecto, lo que se expresa diciendo que un objeto está contenido bajo un concepto" (Kant, 2010, p. 175). Sin embargo, los conceptos puros son heterogéneos, por consiguiente, cuando son procesados por la mente, su representación categorial indica claramente que no son equivalentes al objeto.

Kant busca una salida a esta contradicción y postula la existencia, entre la categorización y los fenómenos, de un tercer término que hace posible la representación no empírica, pero sí intelectual y sensible de los objetos en los conceptos. A este término lo denominó esquema trascendental, el cual lleva implícito la categoría tiempo que permite la relación entre las representaciones formales de lo diverso. En ese sentido, esta categoría es doblemente homogénea, por una parte, es una manifestación universal a priori, y por otra parte, al permitir la relación entre las representaciones de lo diverso, esta es parte consustancial de cada representación, y por tanto, homogéneo a estas. Así, el conjunto tiempo, las relaciones entre las representaciones y las representaciones, forman el esquema trascendental, que es un microsistema que permite la categorización de los fenómenos como conceptos objetos de conocimiento:

[...] la única manera mediante la cual los objetos nos son dados es una modificación de nuestra sensibilidad [...] los conceptos puros a priori, además de la función que realiza el entendimiento en la categoría, deben aún encerrar las condiciones formales de la sensibilidad (especialmente del sentido interno) que contiene la condición que permite tan solo a la categoría aplicarse a no importa qué objeto. Esta condición formal y pura de la sensibilidad, la llamaremos esquema de este concepto del entendimiento, y al método que sigue el entendimiento respecto a este esquema, el esquematismo del entendimiento puro (Kant, 2010, p. 176). 
Un aspecto importante señalado por Kant es que, un esquema puede tener dos orígenes: la realidad y la imaginación. Esto favorece la distinción entre la imagen y el esquema. Cuando esta diferenciación es posible, el esquema es la representación de un procedimiento, que encierra en un concepto su imagen. De esto se sigue que, en la realidad, los conceptos constituidos como objetos mentales no tienen como fundamento las imágenes representacionales, sino esquemas:

Cuando dispongo cinco puntos unos a continuación de los otros [...], doy la imagen del número cinco. Por el contrario, cuando no hago sino pensar en un número en general, que puede ser cinco o ciento, este pensamiento es la representación de un método destinado a representar una multitud (por ejemplo, mil) en una imagen, de acuerdo a un determinado concepto, más bien que esta imagen misma, que sería difícil, en último caso recorrerla con los ojos y compararla con el concepto (Kant, 2010, p 177).

Este principio está en el intelecto, es un acto escondido en las profundidades del ser humano, cuyo mecanismo natural es difícil de determinar. Por ello, solo es la imaginación y su poder empírico la que produce al esquema de los conceptos sensibles y de las figuras en el espacio. El esquema, desde esta concepción es un producto, un monograma mediante el cual las imágenes mentales son posibles, y solamente a través de él se ligan al concepto que las representa, aunque no de forma totalmente adecuada:

(...) el esquema de un concepto puro del entendimiento es algo que no puede ser traído a ninguna imagen, no es sino la síntesis pura, hecha conforme a una regla de la unidad por conceptos en general, regla que expresa la categoría, y es un producto trascendental de la imaginación que concierne a la determinación del sentido interno en general, según las condiciones de su forma (el tiempo) con relación a todas las representaciones, en tanto que estas deben encadenarse a priori en un concepto, de acuerdo a la unidad de la apercepción (Kant, 2010, p 178).

Siguiendo la lógica de la exposición, Kant propone una clasificación de esquemas trascendentales prosiguiendo el orden -pero no la cantidad, por eso se pone entre paréntesis los esquemas implícitos- de las categorías trascendentales (cantidad, cualidad, relación y modalidad) y la relación con ellas. Así, el primer esquema lo denomina, esquema puro de la cantidad, porque considera al número como concepto que representa la adición sucesiva a la unidad (esquema de la unidad), es decir, la síntesis de lo diverso (esquema de la pluralidad) realizada por la intuición homogénea totalizadora (esquema de la totalidad), que opera en el tiempo. En este sentido (el esquema de la realidad) se corresponde con la sensación en general, con un grado o cantidad determinada, que ocupa el tiempo, y tiende a la reducción cuantitativa (esquema de la negación), hasta alcanzar el quantum y la esquematización de esta en el tiempo (esquema de la limitación).

En el tiempo, la realidad tiende a perdurar. El esquema de la sustancia es la representación de lo real como sustrato que permanece en el tiempo. Este atributo mental es lo que se mantiene 
como sustrato, en tanto que la sustancia cambia, es decir, el tiempo como entidad inmutable no se transforma, sino que es la existencia de lo cambiante lo que muta en él.

Según Kant, la causalidad de una cosa es lo real, pero una vez que arbitrariamente se estabiliza esta se vuelve efecto de otra, mediante una regla de sucesión de la diversidad. A este proceso es a lo que le llamó esquema de la causa y de la causalidad.

Cada sustancia se determina entre otras cualidades por sus accidentes. Las sustancias tienen permanencia simultánea en la realidad en virtud de la reciprocidad que ellas tienen con sus accidentes -debido a una regla general. Esta determinación que las diferencia o hace ser semejantes ocurre por la estructuración del esquema de la comunidad (reciprocidad) o de causalidad reciproca de las sustancias con relación a sus accidentes.

El esquema de la posibilidad es el arreglo de la síntesis de diferentes representaciones con las condiciones del tiempo en general. Es decir, la representación de una cosa ocurre en un tiempo, y según dónde y cómo se estructure la síntesis representacional.

Finalmente, Kant propone dos esquemas más: el esquema de la realidad como existencia en un tiempo determinado y el esquema de la necesidad como la existencia de un objeto en todo el tiempo.

Todos estos esquemas son para Kant las verdaderas condiciones que dan a los conceptos una relación con los objetos, y por consiguiente, su significación. Las categorías por sí mismas, solo someten la realidad percibida, y no pueden tener uso empírico si no es a través de estos microsistemas que las vuelven operativas y dinámicas para el ser humano. También, es necesario destacar que, los esquemas funcionan considerando el orden de las categorías, el tiempo y sus reglas: la serie del tiempo, el contenido del tiempo, el orden del tiempo, el conjunto del tiempo en relación con todos los objetos posibles, ya sean físicos o abstractos. Son los esquemas los que realizan las categorías restringiéndolas o ampliándolas dentro y fuera de los límites de la sensibilidad, que es el entendimiento; por consiguiente:

Es en el conjunto de toda experiencia posible donde residen todos nuestros conocimientos, y es en la relación general con esta experiencia en lo que consiste la verdad trascendental que precede a toda verdad empírica y la hace posible (...) el esquema no es sino el fenómeno o el concepto sensible de un objeto, en tanto que concuerda con la categoría (...) Las categorías, sin esquema, no son, pues, sino funciones del entendimiento relativas a los conceptos, pero no representan objeto alguno (Kant, 2010, pp. 180-181).

En toda la exposición sobre el esquema trascendental Kantiano, se puede captar la idea de que los esquemas son microsistemas dinámicos, unidades de acción, que a su vez son reglas de construcción de imágenes desde la sensibilidad mental y determinación del tiempo desde el procesamiento intelectual. Es decir, el esquema es un procedimiento (método), cuyo contenido 
está compuesto por las categorías, los procedimientos y la acción, en este sentido, son producto de la experiencia, por consiguiente, mediadores entre el ser y la realidad.

A continuación, se presenta una ampliación de los esquemas kantianos, a partir de la esquematización de Duque (2002). Para esto, se ha considerado completar y comparar las categorías lógicas y las categorías esquematizadoras. Al hacerlo, se vuelven evidentes los esquemas de unidad, pluralidad, totalidad, realidad, negación y limitación, que implícitamente fueron abordados por Kant, aunque sin considerarlos emergencias de la mente -que es parte activa del cuerpo- como lo hizo posteriormente Nietzsche (2000) al expresar que en el cuerpo no hay otra causalidad que la voluntad de la voluntad:

\begin{tabular}{|c|c|c|c|c|}
\hline Titulo & Mediciones & $\begin{array}{l}\text { Categoría } \\
\text { lógica }\end{array}$ & $\begin{array}{c}\text { Categoría } \\
\text { esquematizadora }\end{array}$ & Esquema \\
\hline CANTIDAD & $\begin{array}{l}\text { Serie del } \\
\text { tiempo }\end{array}$ & $\begin{array}{l}\text { Unidad, } \\
\text { pluralidad, } \\
\text { totalidad }\end{array}$ & $\begin{array}{l}\text { Adición sucesiva, } \\
\text { Síntesis de lo } \\
\text { diverso, } \\
\text { Intuición } \\
\text { homogénea } \\
\text { totalizadora }\end{array}$ & lúmero \\
\hline CUALIDAD & $\begin{array}{l}\text { Contenido del } \\
\text { tiempo }\end{array}$ & $\begin{array}{l}\text { Realidad, } \\
\text { negación, } \\
\text { limitación }\end{array}$ & $\begin{array}{l}\text { Sensación } \\
\text { general, } \\
\text { quantum, } \\
\text { esquematización }\end{array}$ & \\
\hline \multirow{3}{*}{ RELACIÓN } & \multirow{3}{*}{$\begin{array}{l}\text { Orden del } \\
\text { tiempo }\end{array}$} & $\begin{array}{l}\text { Inherencia / } \\
\text { subsistencia }\end{array}$ & Sustancia/accidente & Permanencia \\
\hline & & $\begin{array}{l}\text { Fundamento / } \\
\text { Consecuencia }\end{array}$ & Causa / efecto & $\begin{array}{ll}\text { Sucesión } & \text { de } \\
\text { lo diverso } & \end{array}$ \\
\hline & & Comunidad & Acción recíproca & Simultaneidad \\
\hline \multirow{3}{*}{ MODALIDAD } & \multirow{3}{*}{$\begin{array}{l}\text { Complexión } \\
\text { del tiempo }\end{array}$} & $\begin{array}{l}\text { Posibilidad / } \\
\text { Imposibilidad }\end{array}$ & $\begin{array}{l}\text { Ocurrencia de la } \\
\text { representación }\end{array}$ & $\begin{array}{l}\text { Concordancia } \\
\text { de la síntesis } \\
\text { con el tiempo } \\
\text { en general }\end{array}$ \\
\hline & & $\begin{array}{l}\text { Estar-ahi / no- } \\
\text { ser }\end{array}$ & $\begin{array}{l}\text { Realidad efectiva / } \\
\text { no existencia }\end{array}$ & $\begin{array}{l}\text { Estar-ahí en } \\
\text { un tiempo } \\
\text { determinado }\end{array}$ \\
\hline & & $\begin{array}{l}\text { Necesidad / } \\
\text { contingenc ia }\end{array}$ & Existencia & $\begin{array}{l}\text { Estar-ahi en } \\
\text { todo tiempo }\end{array}$ \\
\hline
\end{tabular}

Completado a partir de Duque (2002, pp. 60-62).

Según Carvalho y Parrat-Dayan (2015), son las ideas de Kant -arriba desarrolladas-y los aportes del médico psiquiatra Revaultd' Allonnes, las que influyeron en el concepto de esquema propuesto por Piaget. Así, con el objetivo de analizarlo en la obra piagetiana, como un término central y en evolución, investigan cómo el autor se vale de este para explicar la acción del sujeto durante una situación específica de aprendizaje. Por ello, se pregunta cómo Piaget utiliza a lo largo de sus estudios, el concepto de esquema para explicar el funcionamiento cognitivo del sujeto. 
Ante esta interrogante, se generan dos tesis: (1) para explicar la interacción sujetoobjeto, Piaget necesitaba de un concepto que estuviera ligado directamente con la acción, lo cual le permitió explicitarlo; (2) es posible reconocer elementos que indiquen el uso subyacente del concepto en el trabajo de Piaget.

Para comprobar ambas tesis, siguen las fases evolutivas de la obra del autor fijadas por Parrat-Dayan (1998): fase egocéntrica, fase funcionalista, fase estructuralista y fase de síntesis. En esta última fase, Piaget revalida y rescata los aspectos funcionales de su teoría y conceptos como el de esquema, colocándolo en un plano más amplio y en articulación directa con las demás estructuras cognitivas del sujeto, volviéndolo un objeto de estudio más organizado. A continuación, se presenta una síntesis sobre la evolución que tuvo el concepto esquema en las cuatro fases.

La fase egocéntrica se puede ubicar en los cinco primeros libros (1976/1923; 1993/1924; 2008/1926; 1927; 1932), en los que Piaget apunta al egocentrismo infantil. Sin embargo, solo menciona el concepto de manera eventual, en las conclusiones de "Le jugement et le raisonnement chez l'enfant" (Piaget, 1993/1924), como referencia a los esquemas de atención propuesto por Revaultd' Allones. El concepto aparece en diferentes partes de la obra, pero debe considerarse como una idea germinal, que convive con otros términos para hacer referencia a esa función psicológica. Por ello, se identificó la necesidad de un concepto que funcionara junto con el de egocentrismo - sin reducirse uno en el otro- para explicar el funcionamiento del sujeto.

En la fase funcionalista, Piaget utilizó el concepto de esquema para estudiar el funcionamiento del sujeto a partir de los estudios presentados en el libro "La naissance de l'intelligence chez l'enfant" (Piaget, 1977/1936). Considera los esquemas como procesos organizados y dirigidos a situaciones específicas de aprendizaje. Caracterizó el proceso de su formación y funcionamiento como una tendencia a las repeticiones y a la acumulación en cada estadio de desarrollo, lo cual favorece que el sujeto interactúe con el medio. Así, los esquemas evolucionan por diferenciaciones cuando ocurre un tipo de especialización o por coordinaciones cuando dos esquemas se combinan o uno de ellos asimila al otro. Esto ocurre en relación con la acción del sujeto, en una situación específica cuando se da la acomodación de los nuevos objetos a los esquemas asimilados. En esta fase, ya Piaget explicó mejor el concepto de esquema, profundizó tanto en su sentido teórico cómo su participación en el funcionamiento cognitivo del sujeto.

Durante la fase estructuralista, y en la obra "Le développement de la notion de temps chez l'enfant" (Piaget, 1973/1946), Piaget utiliza explícitamente la idea de esquema. No obstante, se logra interpretar que este es accesorio al concepto de estructura. Esto es así, porque al abordar la noción de tiempo, esta debe ir asociada con otros conceptos como el de velocidad. 
Por esta razón afirma que, existe un tiempo operatorio asociado a los intervalos temporales y la noción de suceso. Así, el tiempo se comporta de manera análoga a las operaciones lógicas, que están estrechamente conectadas con la noción de velocidad. Es decir, este concepto de tiempo debe considerarse un esquema que se va formando y diferenciando a lo largo del desarrollo del individuo. De esto se deriva, que el concepto de esquema se considera similar a la noción de estructura. Esto es así, porque entre ambos conceptos se observa continuidad, y a su vez, comparten diversas características.

Finalmente, la fase de síntesis de los estudios Piagetianos, se desarrolla en las obras que abordan la discusión sobre lo posible y lo necesario (Piaget, 1981 y 1983). En estas se emplea el concepto de esquema, colocándolo explícitamente de forma solidaria al de estructura. Los esquemas son la parte operacional de la estructura, la cual aporta el soporte necesario para que los esquemas puedan asimilar lo real.

A través de un sistema operatorio y esquemático conformado principalmente por esquemas representativos y procedimentales - se combinan y son la esencia de la noción de esquema- el sujeto actúa en situación. Por ello, este sistema está mejor organizado y adaptado a las situaciones de la vida cotidiana.

Otro aspecto relevante es que, los esquemas del sistema operatorio son más plásticos y de cierta manera diferentes para cada sujeto. De modo que, conceden a cada uno cierta cantidad de posibilidades de acción en cada momento. Así, cada sujeto puede enfrentar diferentes situaciones con este sistema, porque sus esquemas son diferentes tanto cualitativa como cuantitativamente.

Se infiere de estas obras, que los esquemas funcionan como un sistema diferenciado, pero solidario. Esta diferenciación los convierte en dos subsistemas específicos: los esquemas representativos se orientan a la estructura y los procedimentales a la integración de objetos. Así, existe una gran variabilidad en los primeros, porque dan un carácter personal al aprendizaje y la acción de los sujetos, pero esto se restringe en los segundos.

Piaget, en esta fase, mantiene el concepto de esquema orientado a las situaciones, como activadoras de los esquemas procedimentales. Es decir, estos favorecen las operaciones asimilación, compensación y acomodación, asociadas con mecanismos de apertura y cierre de estructuras, por esta razón, relacionadas con la posibilidad y necesidad de formar esquemas representativos.

\section{Conclusiones}

La perspectiva teórica presentada conforma la base para comprender qué son los esquemas de aprendizaje. Este concepto, que no es nuevo en los campos conceptuales de la filosofía, la psicología, la epistemología, entre otras ramas del conocimiento humano, se ha convertido en 
un potente desarrollo teórico que propone, en el campo del aprendizaje el sistema conceptual que permite analizar esta función mental inherente al ser humano.

Por ello, la propuesta de cuatro subesquemas acción: conceptual-factual, lingüístico, sociocultural y técnico-procedimental, es un instrumento de análisis, comprensión, generación y evaluación del aprendizaje (en diferentes situaciones). Esta, que se está poniendo en práctica en contextos reales y dinámicos de aprendizaje, promete ser la base para el desarrollo de las competencias, por consiguiente, una herramienta potente para los estudiantes y docentes de los diferentes niveles y campos de aprendizaje del lenguaje y ramas de las ciencias sociales.

\section{Referencias bibliográficas}

Carvalho, G. y Parrat-Dayan, S. (2015). Recortes históricos sobre a noção de schème em Piaget: o processo de desenvolvimento de um conceito. Revista Brasileira de Estudios Pedagógicos. Vol. 96, $N^{\circ} .24$, pp. 522-540.

De la Torre, E. y Navarro, R. (1982) Metodología de la investigación bibliográfica, archivística $y$ documental, es la base de la ciencia. MacGraw-Hill: México.

Duque, F. (2002). La fuerza de la razón. Invitación a la lectura de la "Crítica de la razón pura" de Kant. Madrid: Dykinson.

Escobar, A. (2016). Esquemas de aprendizaje de la gramática. Tesis Doctoral. Managua: UNAN-Managua.

Kant, I. (2000: a). Crítica del juicio. México: Editores Mexicanos Unidos.

Kant, I. (2010: b). Crítica de la razón pura. Buenos Aires. Argentina: Aguilar.

Kant, I. (2010: c). Crítica de la razón pura. Buenos Aires. Argentina: Alfaguara.
Luhmann, N. (2002). Introducción a la teoría de sistemas. ( $1^{\text {a }}$ reimp.). México: Universidad Iberoamericana.

Maturana, H. y Varela, F. (2003). El árbol del conocimiento. Las bases bilógicas del entendimiento humano. Buenos Aires, Argentina: Lumen.

Parrat-Dayan, S. (1998). Égocentrisme enfantin: concept structure lou fonctionnel? En Bulletin de Psychologique. Vol. 51 (5) set-out.

Salatino, D. (2009). Semiótica de los sistemas reales. Análisis semiótico de la emergencia psico-bio-socio-cultural. (Tesis de doctorado). Mendoza, Argentina: Universidad de Cuyo.Recuperado el 15 de marzo de 2013 de http://www.academia. edu/778540/SEMI\%C3\%93TICA_DE_ LOS_SISTEMAS_REALES

Sierra, Bravo. R. (1986). Tesis doctorales $y$ trabajos de investigación científica. Thomson: Madrid. 